\title{
Sustainable Manufacturing Modelling: A Case for Milling Process
}

\author{
Karmjit Singh and Ibrahim Sultan
}

\begin{abstract}
In manufacturing industries, metal machining is very important process due to the competitiveness. Every manufacturer needs quick, effective and optimized processes. The experience of the operator plays a major role, but even for a skilled operator it is very difficult to attain the optimum values each time. Sustainability Analysis has attracted growing interests from industry, as an optimum cost estimation system analysis method, and energy consumption progress has been achieved. In this work, scrap production as well as production lead time have to be reduced and machining cost per $\mathrm{kg}$ of material is target. To reduce the cost, energy consumption and material wastage impact of the milling process worldwide many aspects of the process are investigated. In the present work, a system has been proposed, which can be used to determine various components of Sustainability analysis of milling process.
\end{abstract}

Index Terms-Sustainability analysis, milling process, energy consumption, metal machining.

\section{INTRODUCTION}

With the increasing cost and scarcity of natural resources, saving environment is getting more attention of the policy planners. The major environmental damage sector in the world are: industrial, transportation, residential and commercial sectors. Around one third of $\mathrm{CO}_{2}$ emissions comes from industrial sector in which manufacturing is a major part. Energy, $\mathrm{CO}_{2}$ emissions and material wastage are important indicators for assessing sustainability [1]. However, Sustainable energy is an energy system that serves the needs of the present without compromising the ability of future generations to meet their needs [2].

This work focus on the energy consumption in milling process along with environmental and wastage during the manufacturing of a new product. In manufacturing processes, Milling is consider as the most common form of machining, a material removal process, which can create a variety of features on a part using mass reduction steps. In milling process rotary cutters are used to remove material from a workpiece by advancing (or feeding) in a direction at an angle with the axis of the tool.

Manufacturing industries need to consider and initiate the implementation of sustainable frameworks and tools to improve their economic benefit and environmental performance [3]. To help the industries, it is pertinent to develop the needed measurement science methodologies and related standards to evaluate and improve sustainability of manufacturing processes. Focusing on energy alone, the U.S.

Manuscript received September 12, 2018; revised December 18, 2018.

The authors are with Federation University, Australia (e-mail: karmjitsingh@students.federation.edu.au). industrial sector consumes about $31 \%$ of the total energy [4]

\section{RELATED WORK}

Earlier, researchers have investigated performance evaluation and improvement for manufacturing process variable consumption. This section reviews related work on sustainability assessment and environmental issues in the machining processes. A few papers on energy and material usages in different machining processes have also been discussed.

Bhanot et al. [5] proposed a framework to analyze different machining processes based on environment and economic indicators. This work also contributes towards optimization of environment and economic indicators such as cost per component and energy consumption by using different optimization techniques. Kim et al. [6] proposed a decision-guidance structure to improve sustainability in manufacturing. This framework mainly consist six different phases: goal and scope definition, collection of data, generate model, sustainability process analysis, implementation and decision making. For implementation of this methodology step turning was performed on CNC machine. Thiriez et al. [7] proposed an approach to identify the effect of different types of machines on energy consumption. They accounted the environmental impact of different machines on the basis of energy supplied. Feng and Juong [8] proposed a framework for quantitative measurement of sustainability for machining operations. A science based methodology has been proposed to calculate the various indicators of sustainable manufacturing. They take into consideration carbon emission and energy use in their study. Kellens et al. [9] proposed a life-cycle analysis oriented methodology for inventory analysis of use phase of unit manufacturing processes. The methodology consist screening and in-depth approach to perform engineering calculations like energy use, material loss, time, power and emission study. To ensure optimal reproducibility and applicability, documentation guidelines were included in both approaches. The aim of this work was to provide high quality data for use phase of unit manufacturing processes. Kellens et al. [10] proposed two case studies for the implementation of LCA oriented methodology. For screening approach a case study of drilling process was consider to calculate energy use and material loss. For in-depth approach laser process was consider to calculate the environmental impact as well as time and power study. Alvarez et al. [11] mainly focus on the sustainability of machining processes. This work has been achieved on the basic of the pillars of sustainability, economic, environmental and equity as an opportunity to improve towards excellence 
and present more reliable and useful solutions. These are the main objectives of present work.

- To determine performance metrics for milling process.

- To propose a methodology for determining science based measurements of the milling process.

- To develop a model that could evaluate sustainability of milling process from process plan of the part with the help of MATLAB Software.

\section{Sustainable Modelling of Milling Process}

In order to assess a manufacturing process efficiently in terms of environmental impact, energy consumption and material wastage, the concept of a unit operation is applied. The unit process consists of the inputs, process, and outputs of an operation. Each unit process is converting material/chemical inputs into a transformed material/chemical output [12]. The unit process diagram of a milling process is shown Figure 1.

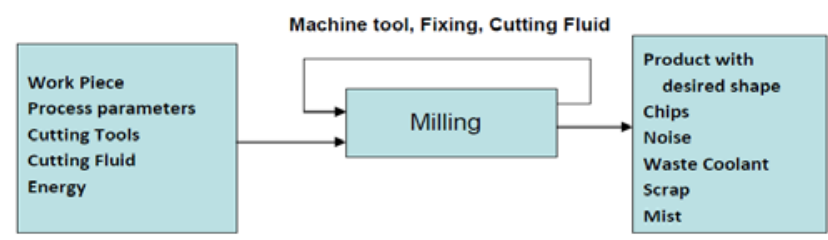

Fig. 1. Input/output diagram of milling process.

A computer aided system for sustainability analysis of milling process has been discussed in this section. The proposed system would help the manufacturing industry to determine sustainability indicators. The system uses knowledge-base of milling process in terms of time calculations, mass loss, energy consumption, power etc. System utilizes coded empirical relations, user input and database for the determination of sustainability indicators.

Sustainability analysis of milling process work on the algorithm which has been developed. Sustainability analyzer algorithm is divided into three modules namely, input module, processing module and result and, report generation module.

\section{PARAmeters AfFecting THE ENERGy REQUiRED FOR MILLING}

An approximate importance of the many variables in determining the milling energy requirements was used to rank parameters from most important to lower importance as follows:

- Workpiece Material properties

- Feed rate

- Cutting speed

- Cutter diameter

- Milling time

- Depth of cut

- Coolant

- Part holding fixture

- Tool wear

- Geometry and set-up.
From this parameter list, only the top 6 were selected for this work while the others having lower influence on energy. Energy required for the overall milling process is also highly dependent on the time taken for idle and basic operations.

\section{SySTEM ARCHITECTURE}

In this section, architecture of sustainability analyzer has been discussed. The system architecture explains various steps involved in sustainability analysis of milling process by using the proposed system. The system architecture of the proposed system i.e. sustainability analyzer can be explained with the help of Fig. 2.

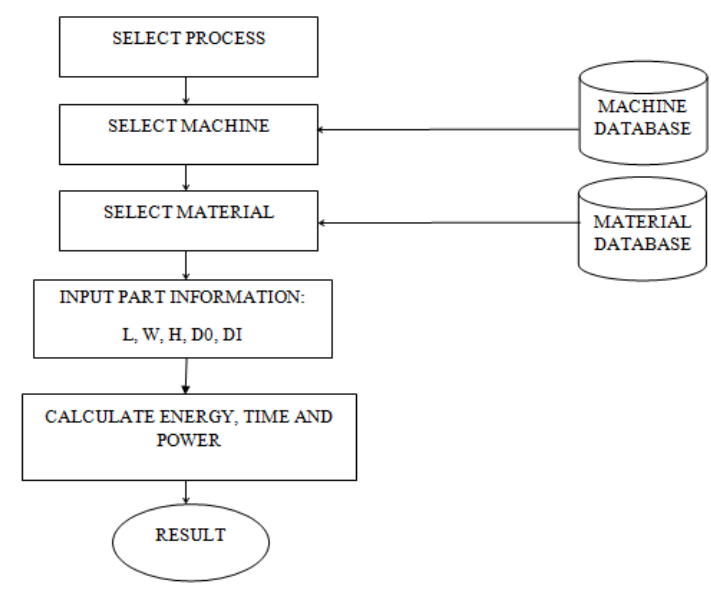

Fig. 2. System architecture.

The milling process is material specific as the selection of material, machines and its parameters are governed by the properties of metal. Therefore, the first step is to select the process and second step is to select the machine for the given product. The system reads alloy properties from the alloy database that has been stored as XLS file. The third step is to select the material. After selecting the material from material database, by the user system determines the sustainability indices i.e. energy, time and power. In the last step results are displayed in the system and these results along with input parameters are stored in the text file.

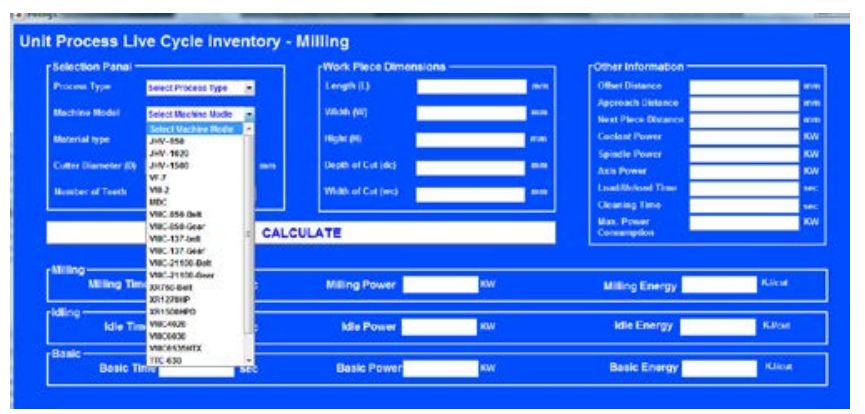

Fig. 3. Snapshot of GUI milling process.

\section{SYSTEM IMPLEMENTATION}

A computer aided system for the sustainability analysis of milling process has been developed on Microsoft Windows XP platform with $3.00 \mathrm{GHz}$ processor and $2 \mathrm{~GB}$ RAM in the MATLAB 12.0 environment. This is a special purpose computer program for performing engineering and scientific 
problems. To give program a pictorial interface MATLAB graphical user interface (GUI) is used which makes the system easy to use by providing buttons like edit, push buttons etc.

\section{CASE STUDY}

To demonstrate the utility of a proposed computer aided system for the sustainability analysis of milling process a case study has been presented.

Proposed system takes required information such as mass of charge, time per cycle and offset information etc. Thereafter, system process the input information for the determination of sustainability indices. System also uses various databases such as material, alloy, machines database and theoretical formulae coded into the system for the determination of sustainability indices. For the validation of proposed system, system results have also been compared with the actual measured data from industry.

For this work we are assuming an aluminum alloy as a work piece. The work piece is a rectangular block of dimensions $500 \mathrm{~mm}$ x $100 \mathrm{~mm} \times 60 \mathrm{~mm}$ (L x H x W). The objective of the study is to analyze the energy consumption in milling cross section of the cut $\left(\mathrm{w}^{*} \mathrm{~d}\right)$ with a $150 \mathrm{~mm}$ diameter cutter with depth of cut of $3 \mathrm{~mm}$. The product dimensions are shown in Fig. 4. From the dimensions and the density the weight of the workpiece is $8.14 \mathrm{~kg}$.

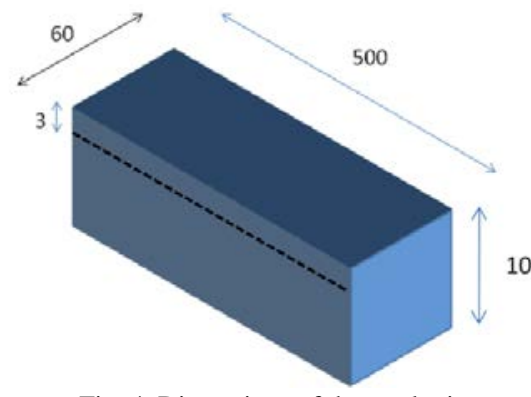

Fig. 4. Dimensions of the work piece.

TABLE I: CUTTING CONDITIONS FOR MILLING PROCESS

\begin{tabular}{|c|c|}
\hline \multicolumn{2}{|c|}{ Cutting Conditions } \\
\hline Cutter Diameter (D) & $150 \mathrm{~mm}$ \\
\hline Cutting Speed (V) & $120 \mathrm{~m} / \mathrm{min}$ \\
\hline Feed per tooth (ft ) & $0.381 \mathrm{~mm} /$ tooth \\
\hline Spindle Speed $(\mathrm{N})=\mathrm{V} / \pi \mathrm{D}$ & $255 \mathrm{rpm}$ \\
\hline Number of teeth & 10 \\
\hline Feed rate $(\mathrm{fr})=\mathrm{ft} * \mathrm{~N} *$ No. of teeth & $971.55 \mathrm{~mm} / \mathrm{min}$ \\
\hline Depth of cut (d) & $3 \mathrm{~mm}$ \\
\hline Width of cut (w) & $60 \mathrm{~mm}$ \\
\hline Volume removal rate $(\mathrm{VRR})=\mathrm{w}^{*} \mathrm{~d} * \mathrm{fr}$ & $174,879 \mathrm{~mm} 3 / \mathrm{min}$ \\
\hline Rapid Traverse (horizontal, X,Y) (m/min) & 30 \\
\hline Rapid Traverse (vertical, Z) (m/min) & 24 \\
\hline
\end{tabular}

User enter Input data for milling process and on the basis of this data, sustainability analyzer determines sustainability indices like time, energy consumption and material loss for milling process. The machining conditions and the cutting parameters are listed in Table 1.

\section{SustainABILITy ANALYZER RESUltS FOR MiLling PROCESS}

Input data for milling process have been discussed in the previous section. On the basis of this data, sustainability analyzer determines sustainability indices like time, energy consumption and material loss for turning process. A snapshot of the GUI of the sustainability analyzer have been shown in Fig. 5.

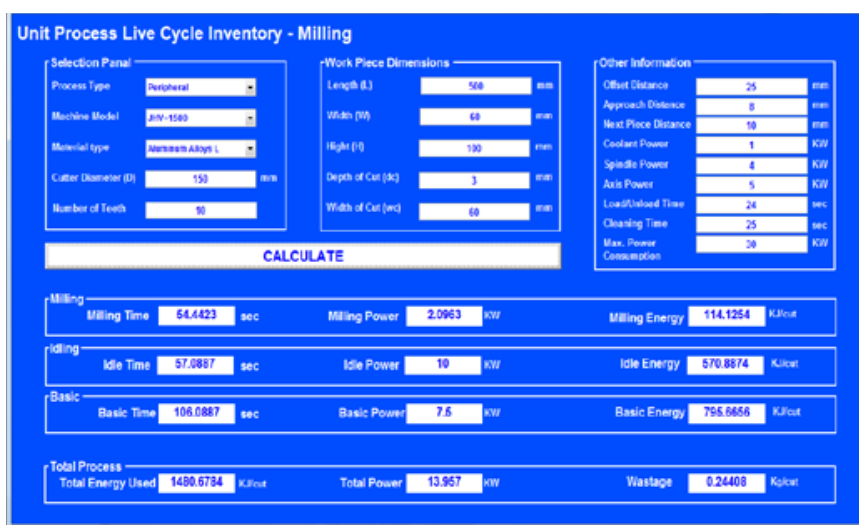

Fig. 5. Snapshot of GUI Milling process.

The proposed system utilizes theoretical formulae for the determination of sustainability indices. Therefore, to check the accurateness of sustainability analyzer, system results have been compared with the actual measured data. The difference obtained by the comparison made is represented with the help of Table 2 .

TABLE II: COMPARISON OF DATA FOR MILLING PROCESS

\begin{tabular}{|c|c|c|}
\hline System Data & Actual Data & \% Error \\
\hline $\mathrm{T}_{\text {tip }}=54 \mathrm{sec}$ & $\mathrm{T}_{\text {tip }}=51.192$ & 5.2 \\
\hline $\mathrm{P}_{\text {tip }}=2.46 \mathrm{~kW}$ & $\mathrm{P}_{\text {tip }}=2.329$ & 5.3 \\
\hline $\mathrm{E}_{\text {tip }}=133 \mathrm{kj} / \mathrm{cut}$ & $\mathrm{E}_{\text {tip }}=122.36$ & 8.0 \\
\hline $\mathrm{T}_{\text {basic }}=134 \mathrm{sec}$ & $\mathrm{T}_{\text {basic }}=125.96$ & 6.0 \\
\hline $\mathrm{P}_{\text {basic }}=7.5 \mathrm{~kW}$ & $\mathrm{P}_{\text {basic }}=7.0875$ & 5.5 \\
\hline $\mathrm{E}_{\text {basic }}=1000 \mathrm{kj} / \mathrm{cut}$ & $\mathrm{E}_{\text {basic }}=927$ & 7.3 \\
\hline $\mathrm{T}_{\text {idle }}=59 \mathrm{sec}$ & $\mathrm{T}_{\text {idle }}=56.05$ & 5.0 \\
\hline $\mathrm{P}_{\text {idle }}=10 \mathrm{kw}$ & $\mathrm{P}_{\text {idle }}=9.34$ & 6.6 \\
\hline $\mathrm{E}_{\text {idle }}=590 \mathrm{kj} / \mathrm{cut}$ & $\mathrm{E}_{\text {idle }}=546.93$ & 7.3 \\
\hline $\mathrm{Wastage}_{2}=0.359 \mathrm{~kg} / \mathrm{cut}$ & Wastage $=0.342$ & \\
\hline
\end{tabular}




\section{COMPARISON OF TIME, ENERgy, POWER CONSUMPTION WITH RESPECT TO PER UNIT WASTAGE (KG) FOR FACE AND PERIPHERAL PROCESSES}

Total power, total energy and time taken by the processes in one kilogram of chip mass removal has been compared for both milling operations from the results company management can analyze and can take steps to improve present sustainable state for the milling process.

The results obtained by face milling and peripheral milling for time taken, total energy and power consumption per $\mathrm{kg}$ of chip mass removal has been presented using bar graphs.

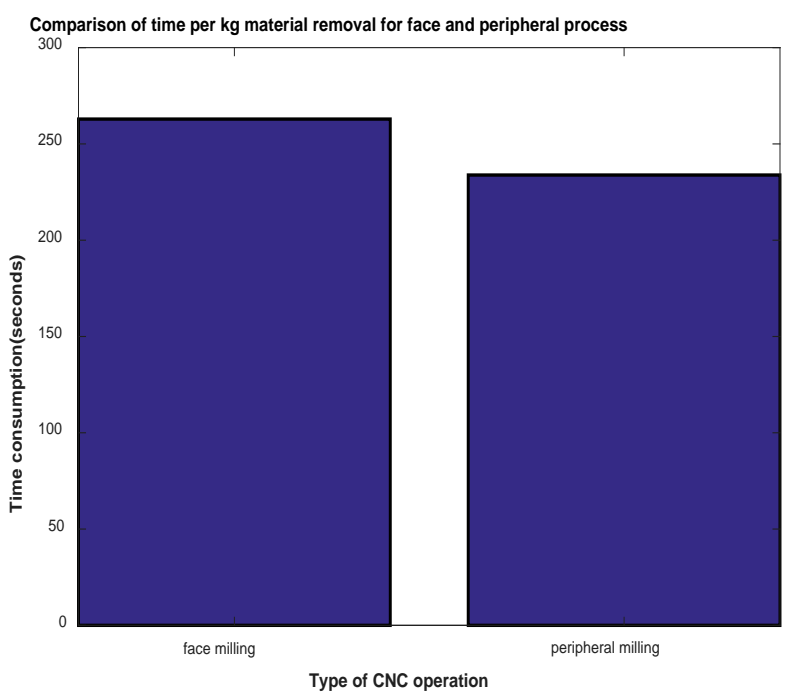

Fig. 6. Comparison of time per kg material removal for face and peripheral process.

Bar graph above shows the time consumed by both processes per $\mathrm{kg}$ mass removal as wastage (face and peripheral milling). It comes out 262.9 and 233.8 seconds for face and peripheral processes respectively.

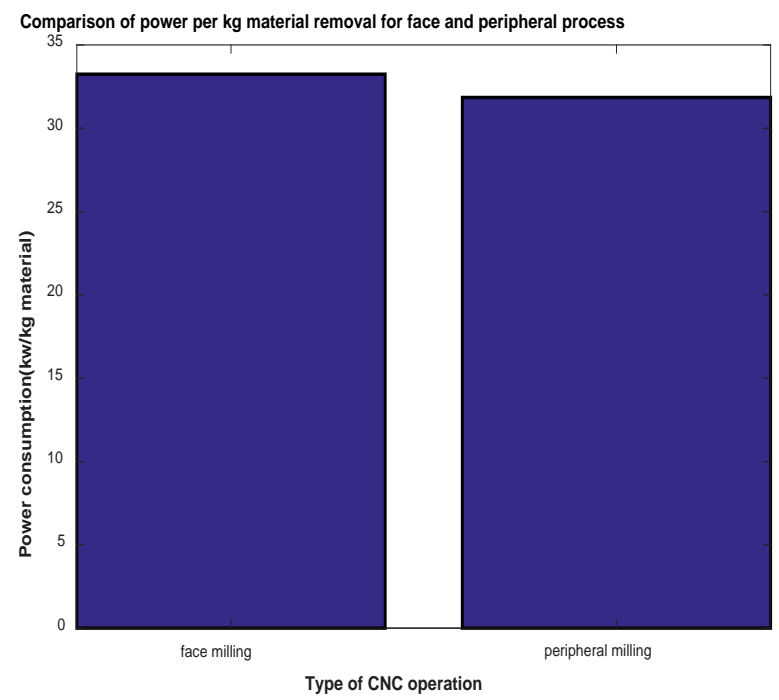

Fig. 7. Comparison of total power per kg material removal for face and peripheral process.

Bar graph above shows the power consumed by both processes per $\mathrm{kg}$ mass removal as wastage (face and peripheral milling). It comes out 33.25 and $31.85 \mathrm{~kW}$ for face and peripheral processes respectively.

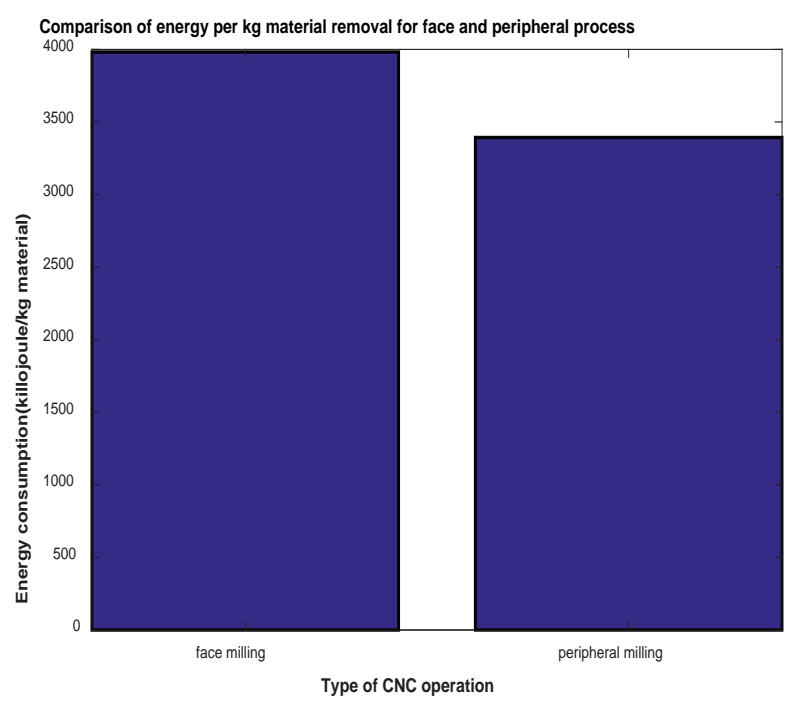

Fig. 8. Comparison of total energy per kg material removal for face and peripheral process.

Bar graph above shows the energy consumed by both processes per $\mathrm{kg}$ mass removal as wastage (face and peripheral milling). It comes out 3982 and 3393 kilojoule/kg for face and peripheral processes respectively.

\section{CONClusion}

In this work, determination of sustainability of milling process has been presented that is based on computer aided system. By using strong database of the process parameters of milling process, the system is built. The sustainability indices used in this work are air emissions, energy use and solid waste. The system prompts the operator to enter the input or choose the value of process parameters. Interaction between the system and user is according the process plan of the product. The proposed system processes the input and gives the output in form of sustainability indices for the process plan of the part. Present system is able to quantify sustainability in terms of sustainability indices. By the system, the sustainability indices are determined that are close to that calculated on the basis of actual measurements of process parameters. Validity and usage of determination of sustainability indices from process plan of a part is shown in this proposed system. The system can also be used to compare two process plans for manufacturing a part and selecting the one with higher sustainability.

\section{REFERENCES}

[1] OECD iLibrary. (2011) Highlights from education at a glance. Education at a Glance 2011. [Online]. Available: http://dx.doi.org/10.1787/eag_highlights-2011-en

[2] K. Singh and I. Sultan, "Framework for sustainability performance assessment for manufacturing processes - A review", in Proc. of International Conference on Sustainable Energy Engineering (IOP Conf. Series: Earth and Environmental Science), vol. 73, 2017.

[3] J. Y. Lee, H. S. Kang, and S. D. Noh, "MAS2: An integrated modeling and simulation-based life cycle evaluation approach for sustainable manufacturing”, Journal of Cleaner Production, vol. 66, pp. 146-163, 2014.

[4] M. Mani, J. Madan, J. H. Lee, K. W. Lyons, and S. K. Gupta, "Sustainability characterisation for manufacturing processes," International Journal of Production Research, vol. 52, no. 20, pp. 5895-5912, 2014.

[5] N. Bhanot, P. V. Rao, and S. G. Deshmukh, "An integrated sustainability assessment framework: A case of turning process," 
Clean Technologies and Environmental Policy, vol. 18, no. 5, pp. 1475-1513, 2016.

[6] B. D. Kim, J. S. Shin, G. Shao, and A. Brodsky, "A decision-guidance framework for sustainability performance analysis of manufacturing processes," International Journal of Advanced Manufacturing Technology, vol. 78, no. 9-12, pp. 1455-1471, 2015.

[7] A. Thirez and T. Gutowski, "An environmental impact assessment of injection molding," in Proc. of IEEE International Symposium on Electronics and the Environmental, 2006.

[8] S. C. Feng and C. B. Joung, "An overview of a proposed measurement infrastructure for sustainable manufacturing," in Proc. of the 7th Global Conference on Sustainable Manufacturing, 2009.

[9] K. Kellens, W. Dewulf, M. Overcash, M. Hauschild, and J. R. Duflou, "Methodology for systematic analysis and improvement of manufacturing unit process life-cycle inventory (UPLCI)—CO2PE! initiative (cooperative effort on process emissions in manufacturing). Part 1: Methodology description,” International Journal of Life Cycle Assessment, vol. 17, no. 1, pp. 69-78, 2012.

[10] K. Kellens, W. Dewulf, M. Overcash, M. Hauschild, and J. R. Duflou, "Methodology for systematic analysis and improvement of manufacturing unit process life cycle inventory (UPLCI) CO2PE! initiative (cooperative effort on process emissions in manufacturing). Part 2: Case studies," International Journal of Life Cycle Assessment, vol. 17, no. 2, pp. 242-251, 2012.
[11] M. E. P. Alvarez, M. M. Barcena, and F. A. Gonzalez, "On the sustainability of machining processes. Proposal for a unified framework through the triple bottom-line from an understanding review," Journal of Cleaner Production, vol. 142, pp. 3890-3904, 2017.

[12] Y. Seow and S. Rahimifard, "A framework for modelling energy consumption within manufacturing systems," CIRP Journal of Manufacturing Science and Technology, vol. 4, no. 3, pp. 258-264, 2011.

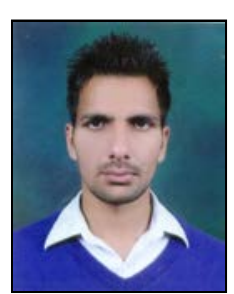

Karmjit Singh is a Ph.D. Research Scholar in the Faculty of Science \& Technology, Federation University Mt Helan Campus, Australia. He completed his B. Tech. and M. Tech. in mechanical engineering (specialization in manufacturing engineering) from Sant Longowal Institute of Engineering and Technology, Sangrur, Punjab in 2012. He previously worked as an Assistant Professor at Bhai Gurdas Institute of Engineering \& Technology, Sangrur, India. He also has extensive industrial experience in product design and quality control in the field of Aluminum Extrusion. His interests include: sustainable manufacturing, $\mathrm{CAD} / \mathrm{CAM}$, machining process optimization. 
Advanced Measurement \& Control Technology and Application 
